\title{
Generations and Protest in Eastern Germany: Between Revolution and Apathy
}

\author{
Philippe Joly \\ Humboldt-Universität zu Berlin \& wzb Berlin Social Science Center, \\ Germany \\ jolyphil@hu-berlin.de
}

\begin{abstract}
How is the protest behavior of citizens in new democracies influenced by their experience of the past? Certain theories of political socialization hold that cohorts reaching political maturity under dictatorship are subject to apathy. Yet, it remains unclear whether mobilization during the transition can counterbalance this effect. This article examines the protest behavior of citizens socialized in Eastern Germany, a region marked by two legacies: a legacy of autocracy and, following the 1989-9o revolution, a legacy of transitional mobilization. Using age-period-cohort models with data from the European Social Survey, the analysis assesses the evolution of gaps in protest across generations and time between East and West Germans. The results demonstrate that participation in demonstrations, petitions, and boycotts is lower for East Germans socialized under communism in comparison with West Germans from the same cohorts. This participation deficit remains stable over time and even increases for certain protest activities.
\end{abstract}

\section{Keywords}

political participation - protest - political socialization - democratization - Eastern Germany

Over the recent years, many studies have examined the effect of political socialization on the evolution of political attitudes and behavior of citizens of

(C) PHILIPPE JOLY, 2018 | DOI:10.1163/15691330-12341481

This is an open access article distributed under the terms of the prevailing CC-BY-NC license at the time of publication. 
new democracies. This strand of research suggests that, on the path to consolidation, new democracies have to overcome legacies of authoritarian socialization (Mishler and Rose 2007; Neundorf 2010; Pop-Eleches and Tucker 2017). Having grown up in a political environment that repressed private, civil, and political liberties, citizens of new democracies have to adjust to the workings of the democratic system. However, since attitudinal and behavioral change becomes increasingly difficult after a certain age, political socialization theories suggest that democratic habituation can only be completed through generational replacement (Mannheim 1952). In the short-term, norms and practices developed in the autocratic period often continue to permeate the political culture of new democracies.

So far, however, this literature has ignored one socialization moment in the political history of new democracies: the transition itself. It remains to be seen whether certain types of transitions from authoritarian rule can induce shifts in the political culture of new democracies. Democratic transitions are often decided behind closed doors, among elites. Yet, sometimes they are also the product of social movements encompassing large segments of society (della Porta 2014). A more optimistic perspective on legacies of political socialization in new democracies would consider the transformative power of bottom-up transitions.

Protest participation is one dimension of political culture that could be affected by bottom-up transitions. Before the consolidation of parties, extraelectoral forms of participation such as demonstrations and petitions are often the most direct and accessible way for citizens to express their political preferences. Peaceful protest activities during a transition can function as "schools of democracy:" They give citizens a feeling of political empowerment, shape new political alliances, and crystallize networks of interest representation. Bottomup transitions represent a rupture with the norm of political disengagement nurtured by authoritarian regimes.

Building on these competing perspectives, this paper examines the effect of political socialization on protest participation in Eastern Germany. From the standpoint of traditional theories of authoritarian socialization, we would expect citizens who grew up under the German Democratic Republic (GDR) to be rather apathetic. The East German communist regime strictly limited the expression of political grievances. Citizens were thus socialized in a political environment that offered little possibility to develop the skills necessary for extra-electoral political activism.

Yet, we must not forget the context that led to the collapse of the GDR. The East German peaceful revolution represents one of the most successful episodes of mass mobilization for democracy in modern history. Without firing a 
gunshot, ordinary people in the streets of Leipzig, Dresden, and Berlin put an end to forty years of dictatorship. This achievement was only possible through the massive involvement of East German citizens. This mobilization might have constituted a defining socialization moment with lasting effects on political participation.

Was the 1989-9o protest wave just a spark of political participation? Did East Germans move from been highly mobilized to being apathetic as predicted by mainstream theories of political socialization? Or did the transitional mobilization have a long-term spill-over effect? Finally, how do these effects vary across generations?

To answer these questions, this study undertakes a systematic comparison of the protest participation of East and West Germans across generations and time. The political participation of West Germans constitutes an interesting benchmark to contrast the effect of radically different experiences of political socialization in Eastern Germany. While previous research has found diverging patterns of protest participation in Eastern and Western Germany (Lahusen and Bleckmann 2015), it is unclear whether these differences are driven by period or cohort effects.

This study pools data collected by the European Social Survey between 2002 and 2017. I use cross-classified, random-effect models to disentangle age, period, and cohort (APC) effects on protest participation among East and West Germans (Yang and Land 2006). Random slopes at the cohort and period levels allow for an estimation of convergence between the two groups. I compare the participation of East and West Germans in three types of protest activities: attending lawful demonstrations, signing petitions, and joining in boycotts.

\section{Political Socialization and Protest in New Democracies}

To explain under what circumstances citizens of new democracies decide to join in protest activities, scholars have first sought to apply general theoretical approaches of protest that were developed in the West European and North American contexts. Grievance, resource mobilization, and opportunity structure theories have improved our understanding of social movement activity after democratic transitions (Gurr 1970; Kriesi et al. 1995; McCarthy and Zald 1977). Yet, these approaches often failed to account for the specific historical situation of third-wave democracies. A small, but growing number of studies has instead looked at historical legacies as determinants of protest participation. These works attempt to explain involvement in extra-electoral political 
actions by looking at the political context in which different generations of citizens were socialized.

\subsection{The Legacy of Dictatorship}

Scholars initially focused on how experiences with the former authoritarian regime affect protest participation in newly democratized societies. This approach builds on a long tradition of research in political science describing democratic consolidation as a process of cultural habituation. According to this perspective, new democracies inherit norms and practices from the former autocratic regime that are incompatible with the workings of the new democratic system. Scholars argue that this mismatch between political cultures tainted by the experience of dictatorship and the democratic institutions is a fundamental challenge for the stability of new democracies (e.g., Almond and Verba 1963). Adjustment to the new system is said to be more problematic for older cohorts who reached political maturity under the previous regime (Mannheim 1952).

This perspective is well-established in the literature on postcommunism. For some authors, the experience of "living through communism" (PopEleches and Tucker 2017) explains why, today, certain generations of citizens in Central and Eastern Europe are less supportive of democracy and the market and are less involved in civic organizations, independent of other sociodemographic and contextual factors (Mishler and Rose 2007; Neundorf 2010; Pop-Eleches and Tucker 2013, 2014).

There are reasons to believe that protest participation in new democracies follows a similar logic of "intergenerational discontinuity" (Mishler and Rose 2007:823). As pointed out by Linz (1975), restrictions on autonomous pluralism are a central feature of autocracies. While traditional authoritarian regimes favor the "passive obedience and apathy" of their "subjects," totalitarian regimes, in contrast, monopolize and exacerbate participation through channels controlled by the political apparatus (Linz 1975:191-92). In one case or the other, citizens have little room to independently organize and articulate public demands. Individuals are socialized in a political environment in which extrainstitutional political participation imposes prohibitive costs on those who practice it. This legacy of dictatorship leaves no fertile ground for the routinization of protest during democratic consolidation.

This pessimistic perspective resonates with empirical findings collected over the last years. A number of studies find that, at the aggregate level, protest is and remains low in new democracies (Bernhagen and Marsh 2007; Roller and Weßels 1996). Some scholars explain this specifically by the duration of 
the former authoritarian regime (Bernhard and Karakoç 2007). Hooghe and Quintelier (2014) go a step further and measure how the participation gap between old and new democracies in Europe varies across generations. Based on theories of authoritarian socialization, we would expect political apathy to be particularly prevalent among older cohorts who grew up under state socialism. The authors, however, do not find significant variation in protest participation across generations. The protest deficit in new European democracies is not substantially lower for younger cohorts. This last finding is surprising and suggests a rather more complex interaction between the current political environment and legacies of autocracy.

\subsection{The Legacy of Transitional Mobilization}

So far, scholars have suggested that authoritarian regimes leave a mark on their citizens. According to theories of authoritarian socialization, citizens who grew up in an environment that restricted autonomous pluralism should be less inclined to join protest activities in the subsequent democratic regime. By focusing only on the impact of the previous authoritarian regime, this literature, however, does not capture the full complexity of the political experience of citizens of new democracies. The democratic transition itself probably constitutes one additional "socialization moment" that should be considered.

While successful transitions are often completed in a matter of months, they remain emotionally charged political junctures that shape the way politics is done during democratic consolidation. When transitions are not only the product of "pacts" among elites, but also build on the participation of large social movements, they can have a more disruptive effect (Fishman 2017). As suggested by della Porta, "protests, particularly the intense moments of mobilization for democracy, are therefore understood as eventful, given their capacity to transform structures through relational, emotional, and cognitive mechanisms" (della Porta 2016:3). Through mass mobilization, the social structure that was artificially flattened out under authoritarianism resurfaces (Weßels 2003). Protest activities allow citizens to acquire new civic skills and enable groups to organize themselves around common interests. A successful transitional mobilization could therefore counterbalance the demobilizing effect of a legacy of dictatorship.

This assumption is consistent with the work of social movement scholars looking at the long-term cultural impact of cycles of contention. Tarrow, for example, affirms that "new forms of collective action develop within the experimental context of cycles of protest. The most successful - and the most 
transferable - become part of the future repertoire of collective action even during quieter times" (Tarrow 1995:94; see also Zolberg 1972). Such "spillover" effects of social movements (Meyer and Whittier 1994) have long been observed in the US with the cohort of baby boomers involved in the civil rights, anti-Vietnam war, and women's movements (Jennings 1987; McAdam 1999). Young protesters in the 1960s and 1970s continued to participate for their lifetime. For some authors, the stability of activists' political attitudes and participation over time demonstrated that protest functioned as a catalyst in the formation of political generations (Caren, Ghoshal, and Ribas 2011; Grasso 2016; Quaranta 2016).

\section{Eastern Germany: Two Competing Legacies}

The legacies of dictatorship and transitional mobilization might have both influenced protest participation since 1990 in Eastern Germany. The political trajectory of the region illustrates how different contexts of political socialization could have engendered generational differences in protest behavior.

If, as Mannheim (1952) first suggested, historical circumstances experienced early in life have a durable impact on one's orientations, abrupt regime changes should be associated with generational shifts in protest behavior. In Eastern Germany, one would expect protest shifts to follow the lines of three major generations, each shaped by distinctive formative political experiences over the last century (Neundorf 2010:1102). People of the first generation, born before the 1930s, saw their adolescence and early adulthood marked by the failure of the Weimar Republic and the Nazi dictatorship. The generation that followed, that is, the people born during the 1930s, 40s, 50s, and 6os, experienced early political socialization under the socialist regime of the German Democratic Republic, or GDR. Finally, younger citizens, who were born in the 1970 and later reached political maturity under a reunified, democratic Germany. While the historical events that formed the first and third generations affected the whole German society, the Cold War generation in the East took a different path from its counterpart in the West. The partition of the country marked a regional rupture in the development of extra-parliamentary political participation.

Whereas West Germans experienced the rise of a protest culture in the post-Second World War era (Rucht 1998), their fellow citizens in the East faced closed opportunity structures that strictly limited their capacity to express political dissension (Wielgohs 2008:114-23). The extensive social control 
imposed by the "bureaucratic-authoritarian" leadership of the GDR combined with the specter of a Soviet intervention pushed protest to the margins of society (Kitschelt et al. 1999:25-27; Lohmann 1994:43). For most people in Eastern Germany, disaffection was expressed mainly in the "public-private sphere" (Oswald and Voronkov 2004): It developed through dense friendship networks or church communities, that is, small deliberative spaces where a certain freedom of expression existed (Wielgohs 2008:121). Political protest was not made public. When a wave of demonstrations erupted in 1989, it occurred spontaneously and was not coordinated by preexisting independent groups.

Coming back to the theory of political socialization, this would lead one to believe that the Cold War generation in Eastern Germany ought to be less prone to engage in routinized protest. A legacy of dictatorship is expected to translate into apathy during democratic consolidation. Empirically, this means that the likelihood of taking part in a protest activity should be lower for the Cold War generation in Eastern Germany than for the corresponding generation in Western Germany, after controlling for other individual characteristics.

Conversely, even though the cycle of protest that led to the fall of the communist regime in Eastern Germany did not last long, it proved to be remarkably widespread, peaceful, and effective in bringing political change. The democratization movement started in September, 1989, as weekly peace prayers held in the city of Leipzig and later evolved into a series of demonstrations asking for political liberalization and freedom of movement. Despite serious threats of repression, the protests spread throughout the country (Lohmann 1994). According to certain estimations, between September 9 and November 13, 1989, more than 3 million people took the streets, that is, about $20 \%$ of the population of the GDR at the time (Opp, Voss, and Gern 1995). Demands of protesters - opening of the borders, resignation of leaders of the communist party, and, eventually, reunification - were met rapidly, making the East German revolution one of the swiftest and steadiest in history.

The massive involvement of citizens of the former GDR is also highlighted by findings of social surveys. The second wave of the European Values Study conducted in 1990 gives a snapshot of the protest experience of East and West Germans in the months before reunification (EVs 2015). When asked whether they "have done," "would," or "would never" join in a lawful demonstration, East Germans were far more likely than West Germans at that time to declare having ever taken part in a protest. In fact, among the younger cohorts, East Germans were twice as likely to have ever joined in a protest as shown in Figure 1.

Did the transitional mobilization in Eastern Germany set in motion a protest culture that endured in the post-Cold War era? In light of its achievements, 


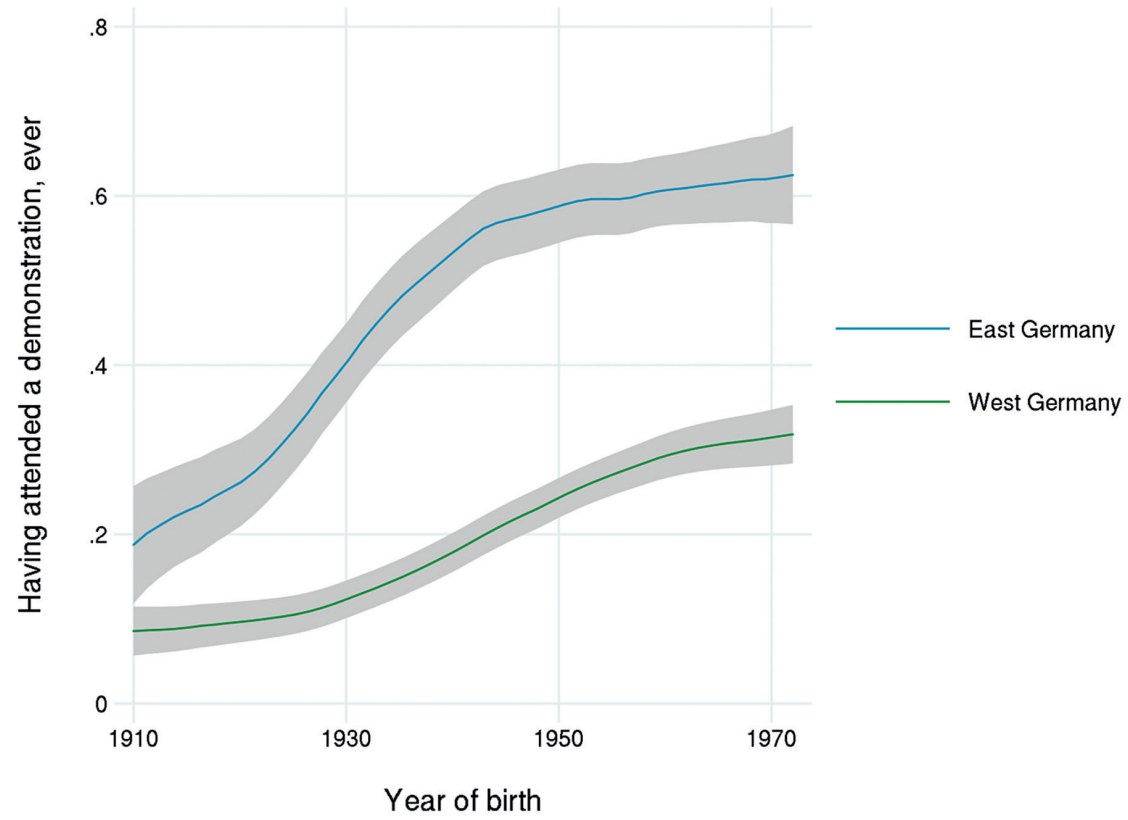

Note: Local polynomial smoothed lines with $95 \%$ CIs

FIGURE 1 Experience with demonstrations across cohorts in East and West Germany in 1990 EVS 2015

the peaceful revolution might have marked a rupture with the legacy of dictatorship. If this were to be the case, the likelihood of taking part in a protest activity should be higher for the Cold War generation in Eastern Germany than for the corresponding generation in Western Germany, after controlling for other individual characteristics.

\section{$4 \quad$ Beyond Political Socialization: Opportunity Structures and Social Compositions}

In order to present a more contextualized account of generational cleavages in extra-parliamentary political participation in Eastern Germany, it is worth considering two complementary explanations. So far, the most common approaches to the study of protest in a comparative perspective have been to look at differences in political opportunity structures and socio-demographic compositions of societies.

In a narrow sense, the political opportunity structure corresponds to the institutional context faced by protesters. As noted by Norris, this includes 
"the constitutional rules of the game" in addition to "overall levels of democratization" and "political rights and civil liberties" (2002:25). These institutional factors determine the level of openness (the input dimension) and capacity to respond to public demands (the output dimension) of political regimes (Kitschelt 1986:61-67). It is usually agreed that closed opportunity structures in authoritarian regimes are the most demobilizing environments for protest. As regimes liberalize and reduce barriers to action, protest expands. Passed a certain level, however, the positive linear relation between openness and protest becomes uncertain (Robertson 2011:19-24). Scholars have been debating whether highly inclusive and responsive political structures continue to further protest - albeit in less disruptive forms (Kriesi et al. 1995) - or if they rather encourage activists to turn to conventional modes of participation (Eisinger 1973; Tilly 1978).

This paper assumes that the institutional convergence after reunification prevents structural factors from playing a major role in regional differences. Contrary to other postcommunist polities, the former GDR abruptly departed from the model of state socialism (Ekiert and Kubik 1998:564). The top-down, Western-led reunification ensured that democratic institutions in the East were rapidly consolidated. The integration in 1990 of the five new German states under an almost un-amended Grundgesetz (the German constitutional law), meant that, in principle, opportunities for political participation and legal protection for the rights of expression and assembly were equivalent in the former East and the former West. Also, at the federal level, the political offer was very similar in both regions of Germany right from the early days of national unity. Already in March 1990, seven months before reunification, the CDU with its "Alliance for Germany" and the SPD had dominated the first (and only) free national elections held in the GDR. With the exception of the former communist SED/PDS (later renamed Die Linke, 'the Left') which remained a significant political actor in the East, the party landscape was rapidly unified after the transition. Therefore, with the same constitutional guarantees, electoral and party systems on both sides of the former wall, the political opportunity structure for protest can essentially be considered constant.

The second alternative explanation takes into consideration individual factors that are not specific to new democracies but are known to influence participation in protest activities more generally. These individual characteristics, when aggregated, generate "compositional effects," which, if they were not controlled for, could lead to the false identification of cohort or period trends (Caren et al. 2011:132; Pop-Eleches and Tucker 2013:50-51). Resources are one important group of factors which should be considered. Previous research has shown that political involvement depends on the access to resources - either 
material (money) or immaterial (time, education, social connections) (Brady, Verba, and Schlozman 1995). There is now a general consensus in the literature that well-connected, educated, and wealthy people are more likely to engage into protest activities. Social connections and education are associated with the development of civic skills while wealth provides the independence necessary to perform political actions. Without being the product of political socialization, cohort differences in protest participation could appear because resources are unequally distributed in Eastern and Western Germany.

The contrasted macro-economic policies practiced on the two sides of the wall and the uneasy monetary, economic, and social union have left distinct socio-economic legacies in the two German regions. During the Cold War, West Germany maintained high productivity levels and was more successful in sustaining economic growth. At the same time, East Germany maintained a policy of full employment with low levels of inequality. Childcare and progressive family models allowed women to be more present in the GDR workforce. Both systems - East and West - achieved almost universal literacy rates. At the eve of reunification, the transition to a market economy was felt hard in the East. Swift privatization of East German state-owned enterprises and, generally, the lack of economic competitiveness in the region led to a sharp increase in unemployment coupled with massive emigration to the West. Since then, economic convergence has progressed, but differences remain (Brenke 2014). In 1991, East Germans' primary income per capita was only $42 \%$ of that of West Germans (excluding Berlin from the ratio). In 2015, it reached $70 \%$ (Statistische Ämter des Bundes und der Länder 2016, 2018). The unemployment gap remained high until the mid-20oos, but has sharply declined since then (Brenke 2014).

Without downplaying the role of these factors, the strategy employed in this study is to assess East-West generational differences after controlling for socio-demographic compositions. As discussed below, the survey data used in the analysis contains information which captures differences in resources between Eastern and Western Germany. The objective is to estimate residual cohort differences which subsist after taking into account these sociodemographic factors.

To measure generational differences in protest participation, we need appropriate empirical data and a modeling strategy that allows for the separate estimation of age, period, and cohort (APC) effects. The literature on political 
behavior suggests that these effects have different sources (see Bartels and Jackman 2014). Age effects are a function of aspects of the life-cycle such as family structures, physical capacity, or simply cumulated life experience. Period effects are produced by structural shocks. For example, we would expect an economic downturn or a national election to exert a temporary pressure on protest. Finally, cohort effects appear through early socialization and are said to remain relatively constant despite advances in age.

\subsection{Data}

Disentangling these three components requires that we have repeated measures so that people of the same cohort are observed at different stages of their life and at different periods. This study pools data collected in Germany during eight rounds of the European Social Survey from 2002 to 2017 (ESS 2017). Over 15 years, the Ess asked Germans and other European citizens about their political beliefs, attitudes, and political participation. The eight rounds incorporated the same core questionnaire which includes questions related to protest participation. To facilitate East-West comparisons, the study excludes citizens who were not born in Germany.

\subsection{Dependent Variables}

The Ess asked respondents whether they had taken part in a lawful public demonstration, signed a petition, or boycotted certain products during the year preceding the survey. These variables are coded as dichotomous. By referring to the 12 months before the interview, the questions of the Ess efficiently capture the temporal variations in the intensity of protest mobilization. The three actions differ in terms of difficulty and with regards to their connection to the past. Signing a petition and avoiding to buy certain products involves lower costs than taking the streets to express political preferences (Rodon and Guinjoan 2018). Also, demonstrations, in comparison to the other activities, are more deeply rooted in the experience of the transition. If the peaceful revolution did leave a legacy of mobilization in Eastern Germany, we would expect this effect to be more visible for demonstrations. Boycotts, in contrast, were largely absent from the repertoire of the 1989-9o mobilization and, in Eastern Germany, a planned economy made it pretty much impossible to organize or join large-scale boycott campaigns.

\subsection{Generations, Micro-Cohorts, and Periods}

Generations are fundamental building blocks of the theoretical model introduced in this paper. Following Neundorf (2010:1102), I define three political generations: 1) the pre-Cold War generation, born before 1929, 2) the Cold War 
generation, born between 1929 and 1969, and 3) the post-Cold War generation, born after 1969. People born before 1920 are excluded from the analysis because of their limited representation in the dataset. Respondents born after 1989 cannot be included in the analysis because the ess did not ask them specific questions related to their migration within Germany (see below).

The boundaries between the generations are set with regards to the political context experienced by citizens during their early formative years. Traditionally, in political socialization research, these years have been situated between mid-adolescence and early adulthood. I follow Grasso's suggested range of 15 to 25 years old (Grasso 2016:40). Two historical moments separate the three generations: first, the creation of the GDR and the FRG in 1949 and, second, the reunification of Germany in 1990. A citizen is said to be part of a specific generation if he or she has spent the majority of his or her formative years in the political context associated with that generation. All Germans aged 20 or less in 1949 - that is, born after 1929 - are part of the Cold War generation since most of their early formative years (at least 6 out of 11 years) were experienced in two separate states. Similarly, citizens aged 20 or less in 1990 - that is, born since 1970 - were mainly socialized in a unified Germany.

Although these historical circumstances are well defined in time, the exact cut-off points between years of birth remain nonetheless arbitrary. As explained by Neundorf, ' $[\mathrm{i}] \mathrm{n}$ reality the transitions between pre-, post- and Cold War generations are seamless' (2010:1105). For this reason, the three political generations serve mainly as theoretical references in the discussion of the results. When performing the actual multivariate analysis to estimate cohort differences, respondents are classified in 14 five-year birth cohorts $\left(\right.$ cohort $_{1920}$ : $1920-24, \ldots$, cohort $_{1985}: 1985-89$ ). Defining this type of micro-cohorts makes the identification of trends less sensible to specific generational thresholds (Caren et al. 2011). Finally, periods correspond to each of the two-year rounds of the ESS (2002-03, ..., 2016-17).

\subsection{Growing Up in Eastern Germany}

The main independent variable in this study indicates whether respondents were socialized in Eastern or Western Germany. This variable goes beyond coding where the interview took place: it retraces where the respondent grew up, even if he or she moved across regions. By leveraging information provided in the Ess German country-specific dataset, I can control for East-West migration within Germany. ${ }^{1}$ A respondent is said to have been socialized in Eastern

1 I am able to identify the region in which the respondent was socialized by combining responses from three questions in the Ess country-specific questionnaire. A first question, 
Germany (coded ' 1 ', otherwise ' 0 ') if he or she has spent the majority of his or her early formative years (from 15 to 25 years old) in this region. With this operationalization, the analysis can sort out the latecomers from the "real" East or West Germans.

\subsection{Control Variables}

As discussed previously, both structural legacies and individual circumstances place citizens in various socioeconomic positions with unequal access to resources for mobilization. The effects of these factors have to be isolated from those of socialization. The analysis controls for the gender of respondents, their age (and age squared), their education level (low, middle, high), their employment status (employed or unemployed), the size of their town (from 1: "a farm or home in countryside" to 5: "a big city"), and their current or previous membership in a labor union (yes or no). Based on Oesch's classification of occupations (2006a, 2006b), I also control for membership in five social classes: higher-grade service class, lower-grade service class, small business owners, skilled workers, and unskilled workers. ${ }^{2}$ I include dummies for the states ("Länder") in which respondents live. Some of the 16 German states might be outliers, with exceptionally high or low levels of protest. State dummies control for structural conditions, such as geography, population density, or economic development, that would not be fully captured by individual-level variables. Finally, I purposefully do not include variables related to political attitudes (e.g. political interest) because these are endogenous to protest. Since the questions on political participation are retrospective, the causal relation between attitudes and behavior might be inverted.

\subsection{Statistical Approach}

Separating the effects of age, periods, and cohorts in a linear model is problematic because these three components are perfectly multicollinear, as in Equation 1.

$$
\text { cohort }=\text { period }- \text { age }
$$

coded by the interviewer, indicates if the interview was conducted in Eastern or Western Germany. A second question asked respondents "Where did you live before 1990?" with two possible answers: "in Eastern Germany / East Berlin" or "in Western Germany / West Berlin." If there was a mismatch between the first two questions, indicating that the respondent moved across regions, a follow-up question asked "when did you move to the eastern / western part of Germany?" With these pieces of information, we can know whether a respondent moved across regions and, if so, at what age (given the respondent provided his or her year of birth).

2 I do not control for income since this variable has a very high percentage of missing values. 
I follow Yang and Land $(2006,2008)$ and perform a series of APC analyses with cross-classified random effects models (CCREM). This type of model bypasses the APC identification problem by specifying period and cohort effects as random instead of fixed and additive. Individuals are assumed to be simultaneously clustered in cohorts and periods.

CCREMS have been previously used to identify cohort and period effects on protest in the United States (Caren et al. 2011) and in Italy (Quaranta 2016). Contrary to other studies, however, this paper does not focus on period and cohort effects per se but rather on how the effect of one predictor of protest growing up in Eastern Germany - varies across generations and time. This can be operationalized by specifying not only random intercepts for cohorts and periods, but also a random coefficient for the variable eastsoc, which indicates whether a respondent has been socialized in Eastern Germany. We can let this coefficient vary across periods and cohorts to model patterns of convergence and divergence between Eastern and Western Germany. Equation 2 details the hierarchical logistic models used in this study. For each of the three protest activities (demonstrations, petitions, and boycotts), I fit two cross-classified models: one with a random-slope at the cohort level and one with a randomslope at the period level.

$$
\operatorname{Logit} \operatorname{Pr}\left(\text { protest }_{i j k}\right)=\beta_{\mathrm{ojk}}+\beta_{1} a g e+\beta_{2} a g e^{2}+\beta_{3 j k} e a s t s o c+z_{i j k}
$$

\section{Random intercept}

$$
\beta_{\mathrm{ojk} k}=\gamma_{\mathrm{o}}+v_{\mathrm{oj}}+v_{\mathrm{o} k}
$$

\section{Random slope at the cohort level}

$$
\beta_{3 j k}=\beta_{3 j}=\gamma_{3}+v_{3 j}
$$

Random slope at the period level

$$
\beta_{3 j k}=\beta_{3 k}=\gamma_{3}+\nu_{3 k}
$$

Here, the logit of the probability of having taken part in a protest activity during the 12 months preceding the survey is a function of the intercept for cohort $j$ and period $k\left(\beta_{0 j k}\right)$, the fixed effects of age and age squared $\left(\beta_{1}\right.$ and $\left.\beta_{2}\right)$, the effect of growing up in Eastern Germany $\left(\beta_{3 j k}\right)$, and a vector covariates $\left(z_{i j k}\right) \cdot \beta_{o j k}$ can be further decomposed into three components: the overall intercept $\left(\gamma_{o}\right)$, the random-intercept of cohort $j\left(v_{o j}\right)$, and the random-intercept 
of period $k\left(v_{o k}\right) \cdot \beta_{3 j k}$ is a combination of the main effect of eastsoc $\left(\gamma_{3}\right)$, and an additional term: either the variation of this coefficient at the cohort level $\left(v_{3 j}\right)$ or the variation of this coefficient at the period level $\left(v_{3 k}\right)$.

\section{$6 \quad$ Findings}

The analysis explores whether the protest behavior of East Germans relative to West Germans is characterized by a legacy of dictatorship or, conversely, by a legacy of transnational mobilization and how this pattern differs across cohorts and periods. Hierarchical APC models estimate, for East and West Germans, the likelihood of having taken part in a protest activity in the 12 months preceding each of the eight ESS rounds conducted between 2002 and 2017.

\section{1 $\quad$ Fixed Effects}

I present full regression tables in the Appendix. Figure 2 shows a summary of coefficient sizes with $95 \%$ confidence intervals for the fixed part of the models

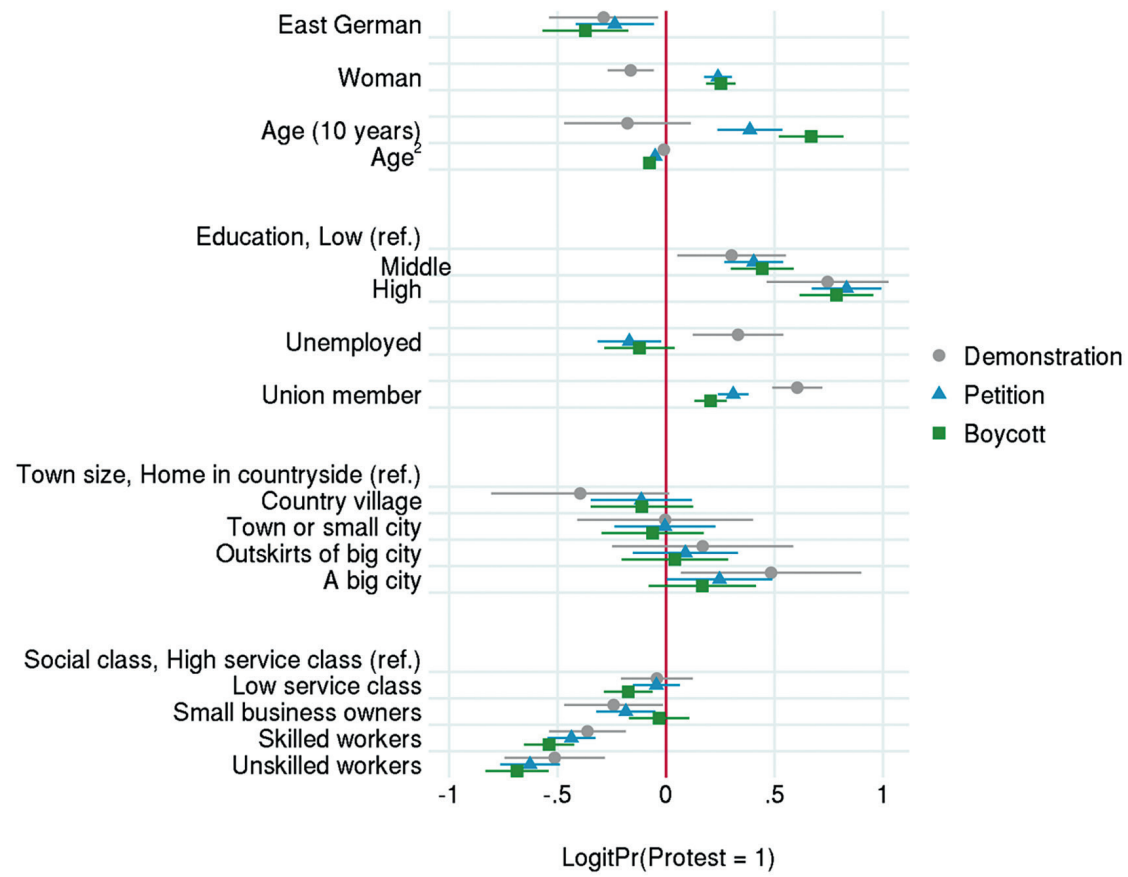

Note: Based on CCREM with random slopes at the cohort level.

FIGURE 2 Coefficient sizes and 95\% CIs

ESS 2017 
with a random coefficient at the cohort level (excluding the effects of states). The results for the fixed part of the models with a random coefficient at the period level are nearly identical and therefore not reported.

For all three political actions, growing up in Eastern Germany has an overall negative effect on protest participation. All other things being equal, the odds ratios of taking part in a demonstration, signing a petition, and joining in a boycott are respectively, 0.75, 0.79, and 0.69 for East Germans in comparison with West Germans. Without further analysis, we can therefore already conclude that the wide diffusion of protest observed in 1989 and 1990 has not been sustained in the 15 years covered by the Ess data. Nowadays, East Germans tend to participate less on a yearly basis than their fellow citizens who grew up in the West.

Looking at the effect of the other covariates, we see that the assumption that resourceful persons have a higher propensity to protest is mostly supported in the analysis. Among the indicators of resources, education and union membership are the two variables which are most consistently associated with protest participation. Educated respondents and union members appear to profit from increased civic skills and denser networks of mobilization. Similarly, respondents from more privileged social classes, especially in the service sector, tend to be more active in all forms of protest. The effect of unemployment, however, is inconsistent across political actions: it is positive for demonstration attendance, but negative for signing petitions and insignificant for joining in boycotts. As expected, large cities offer a more favorable environment for protest, but the relationship between city size and participation appears nonlinear and is not significant for boycotts. The effect of gender varies across types of protest: men are overrepresented in demonstrations, but women are more active in petitions and boycotts. Finally, the effect of age is not significant for demonstration attendance. Yet, for the two remaining forms of protest, it is highly significant and follows an inverted $U$ pattern. The effect of age is maximized at 38 and 44 years old for participation in petitions and boycott, respectively.

\subsection{Random Effects}

We now turn to the random parts of the models. In general, the variance components presented in Tables $\mathrm{A}_{1}$ and $\mathrm{A}_{2}$ in the Appendix indicate that little variation in participation is clustered at the cohort and period levels. Clearly, protest measures incorporate a large stochastic variation and part of the intracluster correlations has already been explained by individual-level variables. Still, some patterns emerge. For demonstration attendance, variances of the cohort and period random intercepts - two measures of the clustering within 
cohorts and periods in the whole German population - roughly have the same magnitude. For petitions and boycotts, however, the cohort effects across Germany are mostly inexistent.

A look at the random slope of eastsoc further reveals how much the effect of growing up in Eastern Germany varies across cohorts and periods. Figures 3 to 5 display the predicted coefficients of the variable measuring whether a respondent was socialized in Eastern Germany, combining fixed and random effects, across cohorts. The vertical dashed lines delimit the pre-, post-, and Cold War generations.

Across all three forms of political participation, the coefficient of eastsoc never passes the ' 0 ' threshold. The effect of growing up in Eastern Germany on demonstration attendance (Figure 3) barely varies across cohorts and remains significantly negative at around -0.3 (odds ratio $\approx 0.74$ ). Generational variation in the eastern participation deficit becomes clearer with petition signing (Figure 4). Although no individual random cohort effect is significantly different from the overall fixed effect, the gap between East and West Germans

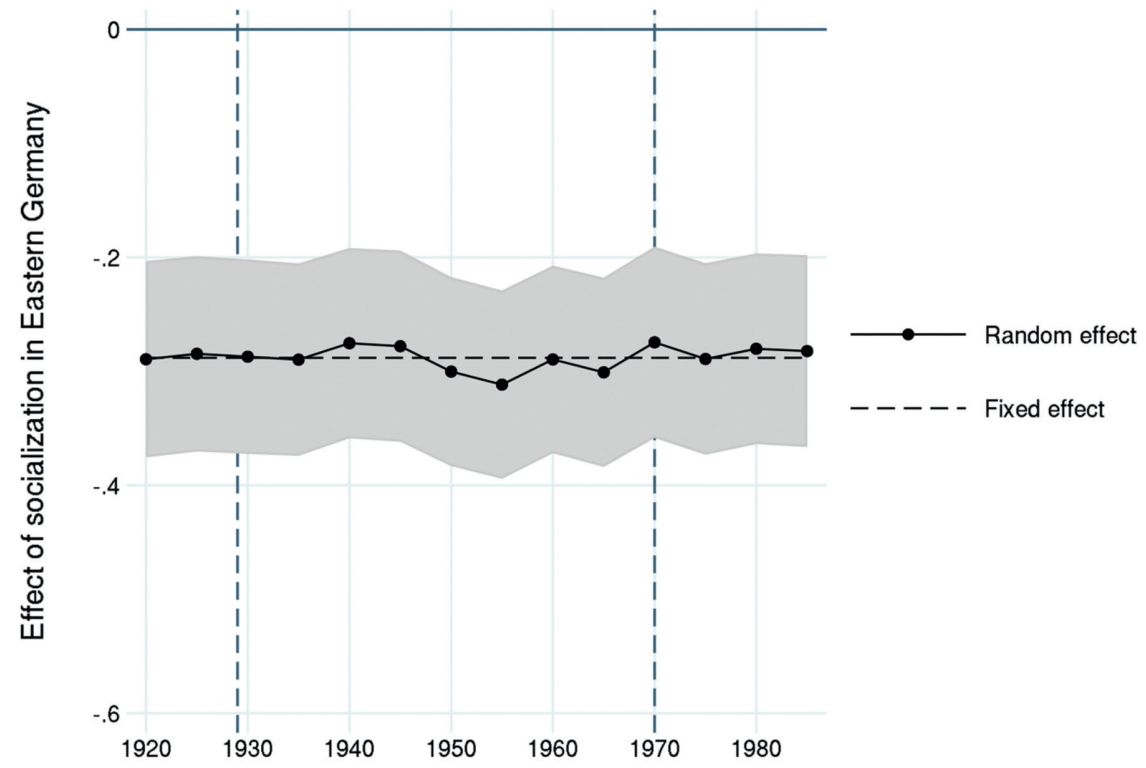

Birth cohorts

Note: Vertical dotted lines indicate the separations between the pre-, post-, and Cold War generations. Grey areas show 95\% confidence intervals of the predicted random effects.

FIGURE 3 Effect of socialization in Eastern Germany on demonstration attendance across cohorts

ESS 2017 


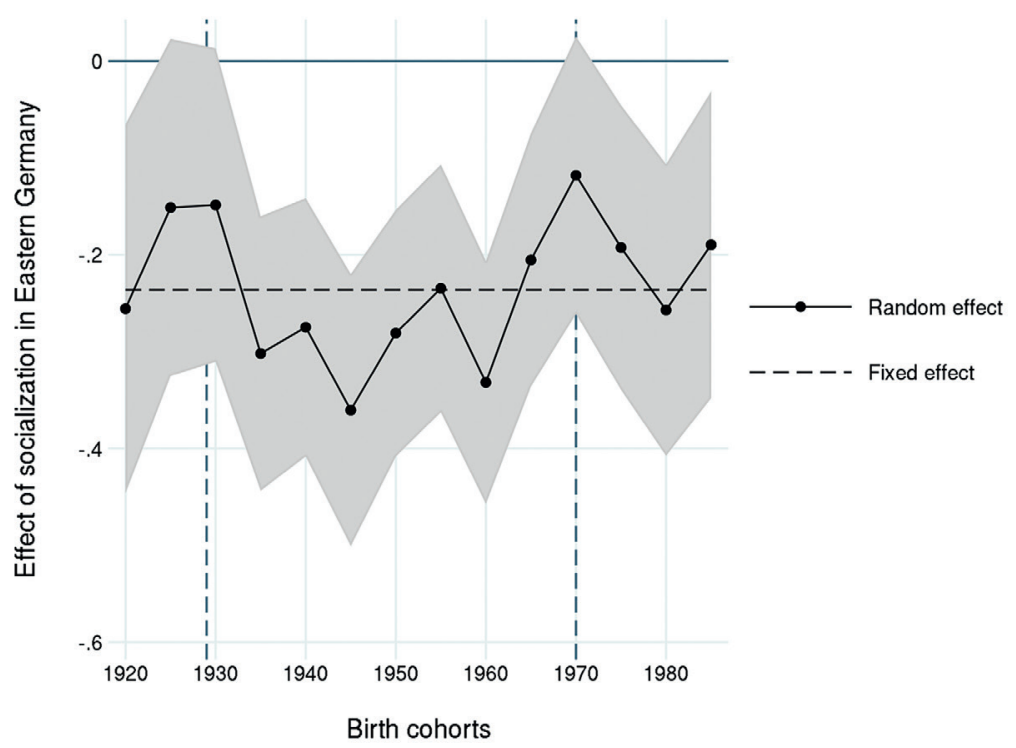

Note: Vertical dotted lines indicate the separations between the pre-, post-, and Cold War generations. Grey areas show 95\% confidence intervals of the predicted random effects.

FIGURE 4 Effect of socialization in Eastern Germany on petition signing across cohort

ESS 2017

appears to be maximized for the individuals of the Cold War generation. East Germans socialized in-between two generations, born around 1930 and around 1970, tend to have a slightly smaller protest deficit. A characteristic U-shaped trend in the cohort effects is apparent for participation in boycotts (Figure 5). East Germans of the Cold War generation born between 1930 and 1960 tend to have the lowest propensity to join in boycotts in comparison with West Germans of the same cohorts. For these respondents, the effect of growing up in Eastern Germany reaches up to -0.5 (odds ratio $\approx 0.61$ ). The East-West gap is sharply reduced for the post-Cold War generation, especially for the cohort born between 1975 and 1979 .

The results of the models with a random coefficient at the period level do not indicate that the East-West gap is about to be bridged. Quite the contrary, Figures 6 to 8 show that, for two of the three protest activities, the eastern deficit in participation has increased over time. Whereas East Germans tended to participate as much as West Germans in demonstrations at the beginning of the 200os, a stable participation deficit is apparent since 2008 (Figure 6). A similar trend can be observed with petition signing (Figure 7). Here, participation has plunged for East Germans in 2010 and remains low since then. Finally, 


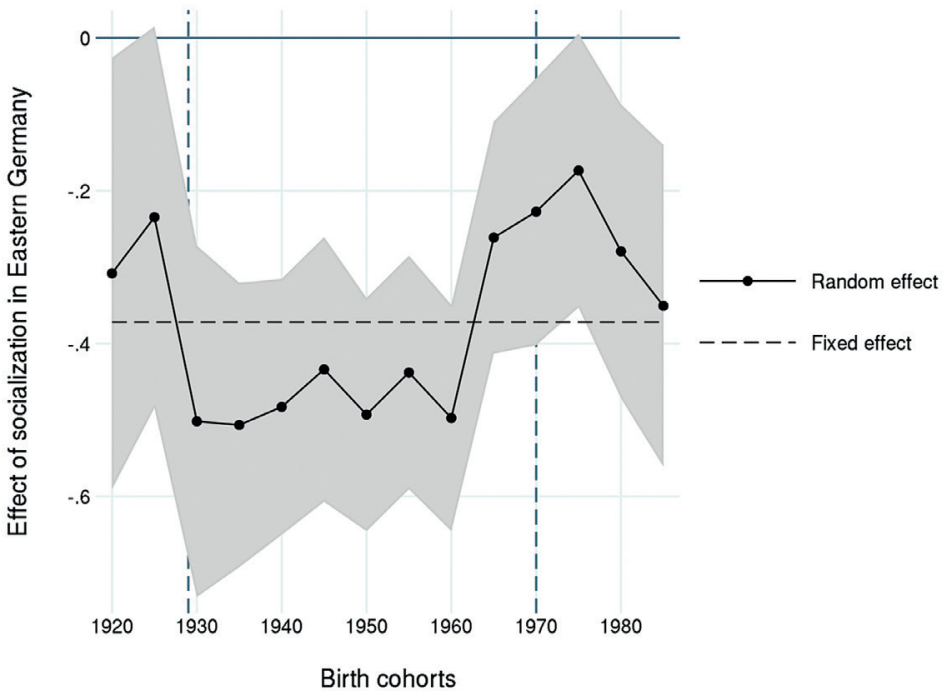

Note: Vertical dotted lines indicate the separations between the pre-, post-, and Cold War generations. Grey areas show 95\% confidence intervals of the predicted random effects.

FIGURE 5 Effect of socialization in Eastern Germany on participation in boycotts across cohorts ESS 2017

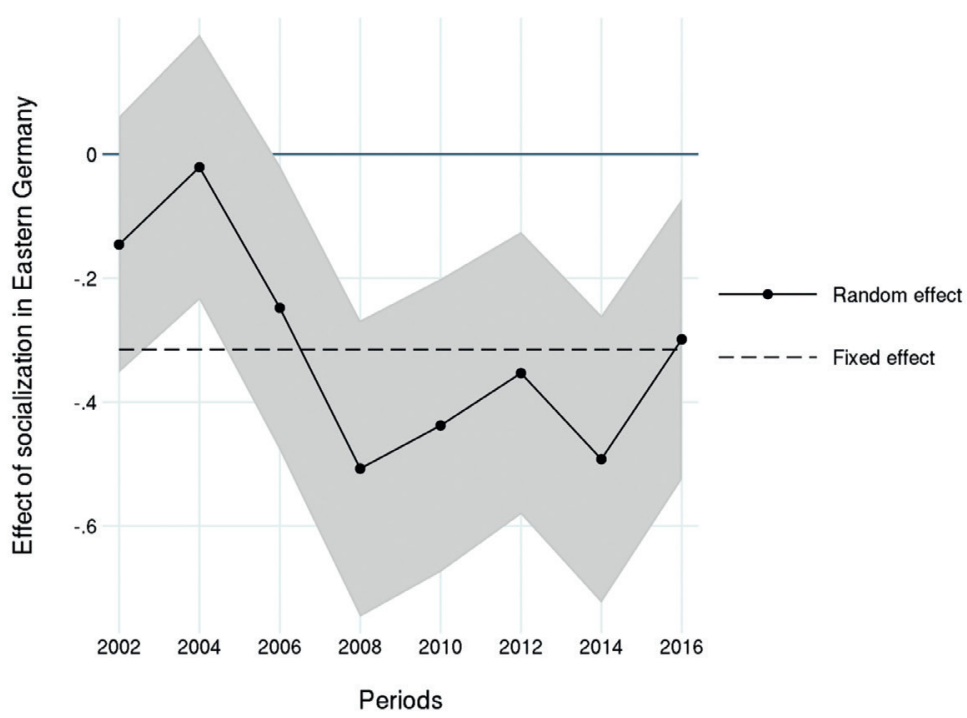

Note: Grey areas show 95\% confidence intervals of the predicted random effects.

FIGURE 6 Effect of socialization in Eastern Germany on demonstration attendance across periods

ESS 2017 


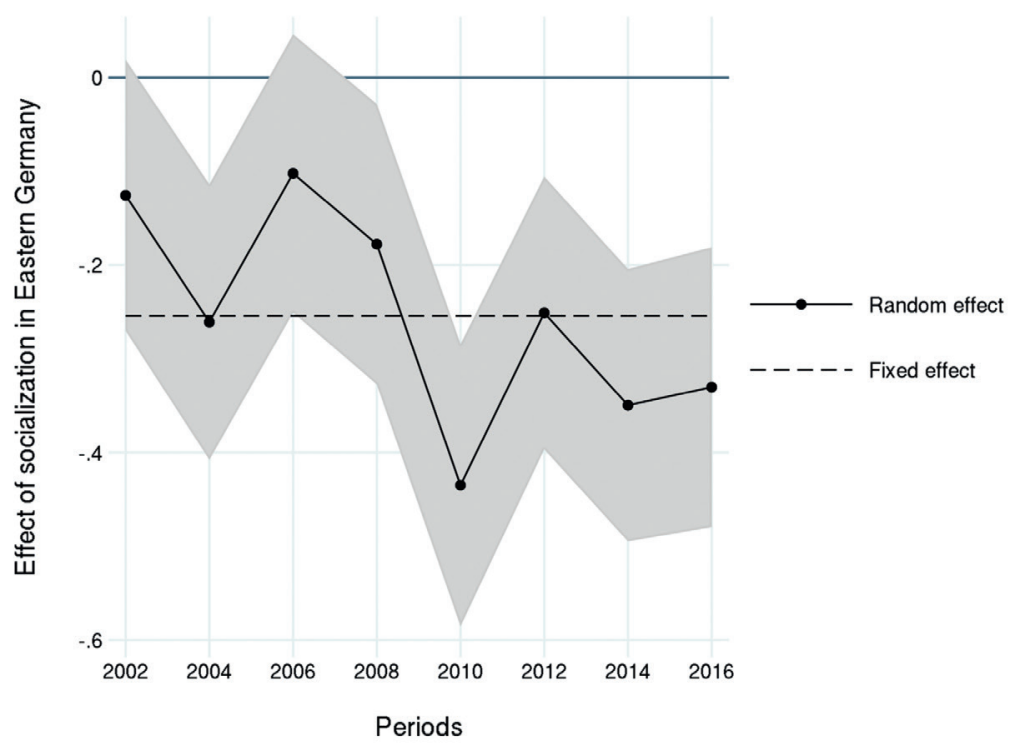

Note: Grey areas show 95\% confidence intervals of the predicted random effects. FIGURE 7 Effect of socialization in Eastern Germany on petition signing across periods

ESS 2017

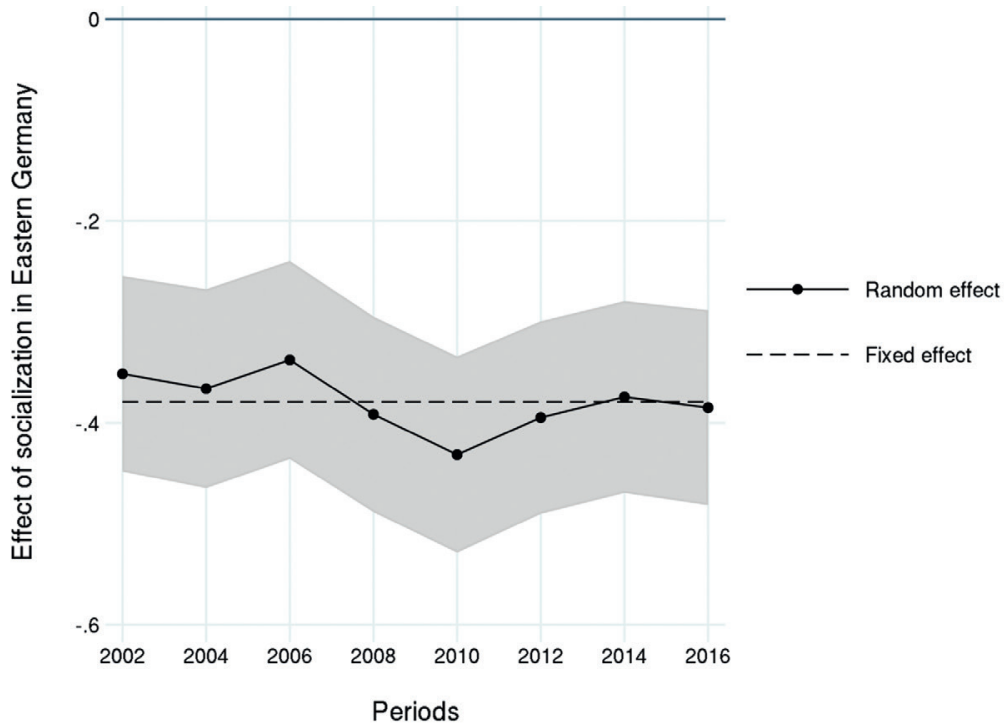

Note: Grey areas show 95\% confidence intervals of the predicted random effects.

FIGURE 8 Effect of socialization in Eastern Germany on participation in boycotts across periods

ESS 2017 
there is little variation over time in involvement in boycotts (Figure 8): the predicted random-effects of the coefficient are nearly indistinguishable from the fixed effect at -0.38 (odds ratio $\approx 0.68$ ).

All in all, these results indicate that the massive involvement of citizens of the GDR during the transition was short-lived. The vast protest experience acquired by East Germans from the Cold War generation in 1989 and 1990 has not been translated into day-to-day extra-parliamentary participation. Rather than a legacy of transitional mobilization, a legacy of autocracy seems to dominate the political landscape in Eastern Germany.

\subsection{Robustness Checks}

I validate these findings in a set of alternative fixed-effect models. An interesting aspect of estimating relative instead of absolute cohort and period effects for East and West Germans is that we don't necessarily need to perform full APC models. If we assume that life-cycle effects on protest are the same for people who grew up in Eastern and Western Germany, then we can leave age out of the equations. ${ }^{3}$ With only two components, periods and cohorts, fixed-effect models can perform as well, if not better, than the random-effect ones. The conceptual logic behind this specification is similar to a proportional hazards model where a baseline hazard function (here the age effect) remains unspecified but is assumed to be the same across groups.

To estimate convergence or divergence in protest participation between East and West Germans across generations and time, I model the propensity to take part in protest with a series of interaction terms: first, between cohorts and the variable measuring whether a respondent was socialized in the East and, second, between periods and the same socialization variable.

$$
\text { LogitPr (protest) }
$$

$$
\begin{aligned}
& =\beta_{0}+\beta_{1} \text { eastsoc }+\sum_{l=2}^{14} \alpha_{l} \text { cohort }+\sum_{m=2}^{8} \mu_{m} \text { period } \\
& +\sum_{n=2}^{14} \gamma_{n}(\text { eastsoc } \cdot \text { cohort })+\sum_{o=2}^{8} \lambda_{o}(\text { eastsoc } \cdot \text { period })+z
\end{aligned}
$$

3 This assumption is not directly testable. Yet, I can verify that generational differences between East and West Germans are not artificially produced by unbalanced age groups. To do this, I fit a linear regression predicting age by socialization in East Germany, cohorts, and periods. The results show that the effect eastsoc is not significant, meaning that there is no significant compositional difference in age between East and West Germans once we control for cohorts and periods. 
In Equation 3, the logit of the probability of ever having taken part in a protest activity is the combination of an intercept $\left(\beta_{0}\right)$, the main effect of eastsoc $\left(\beta_{1}\right)$, the main effect of the cohort of the respondent $\left(\alpha_{l}\right)$, the main effect of the period $\left(\mu_{m}\right)$, the interaction of eastsoc with the cohort of the respondent $\left(\gamma_{n}\right)$, the interaction of eastsoc with the period $\left(\lambda_{o}\right)$, and a vector of covariates excluding age $(z)$.

Figures A1 to A6 in Appendix show the predicted effect of eastsoc across cohorts and periods for each protest activity. The results of the fixed effects models are similar to those of the random effects models. One difference however is that, while with the random effect models the negative effect eastsoc is pronounced but varies little around the mean effect across cohorts, with the fixed effects models we can observe more variability and a clearer inversed bellcurve for all the protest activities. The participation deficit of East Germans reaches its maximum for some cohorts in the Cold War generation. The effect of having been socialized in Eastern Germany is not significant for the pre- and post-Cold War generations. The period effects of the fixed effects models are almost identical to those of the random effects models except for participation in boycotts, where the East-West gap seems to have widened more over time.

In brief, these results tend to confirm the observations made earlier. East Germans have a lower propensity to take part in protest activities and, at least for certain forms of protest, this gap is accentuated for cohorts of the Cold War generation. It is plausible that, after the 1989-9o mobilization, with diminishing returns on political action, citizens in Eastern Germany rapidly developed a protest fatigue. From there, old patterns of apathy forged during the GDR re-emerged.

One of the conditions for the development of a "strong democracy" is that citizens have their say about the way politics is run in between elections (Barber 1984). In that sense, non-violent protest activities such as demonstrations, petitions, and boycotts constitute "an extension of the citizen's political action repertory within the realm of democratic engagement" (Kaase 2007:793).

In new democracies, legacies of the former autocratic regime can hinder the development and normalization of protest. Theories of political socialization suggest that citizens who reach political maturity under autocratic regimes do not have the chance to fully develop their protest skills and therefore are less susceptible to turn to unconventional forms of political participation once democracy is established. This perspective, however, does not consider the 
possibility that mobilization during the transition could counterbalance legacies of the autocratic regime.

This paper has contributed to this discussion by looking at the effects of political socialization on the protest behavior of East Germans, a group of citizens who experienced both a long, rigid bureaucratic-authoritarian regime and a massive mobilization during the transition to democracy (Kitschelt et al. 1999). The paper asked whether the peaceful revolution in East Germany could have left a positive legacy of mobilization for certain generations of citizens.

Using age-period-cohort models with data from the European Social Survey, the study compared the participation of East and West Germans in demonstrations, petitions, and boycotts, across generations and time. The results indicated that the 1989-90 mobilization did not have a lasting effect. In line with more traditional theories of political socialization, East Germans appear to have been less active than West Germans in all three forms of protest between 2002 and 2017. This relative disengagement was particularly visible for cohorts of citizens who grew up during the Cold War. The authoritarian regime of the GDR appears to have left its mark on political participation in Eastern Germany. Nonetheless, the magnitude of the East-West participation gap remains modest and, under certain model specifications, East Germans of the post-Cold War generation do not participate significantly less than West Germans of the same cohorts. Apathy, therefore, is not as pervasive as one might fear among East Germans.

Eastern Germany constitutes a single, but emblematic, case of "eventful transition" (della Porta 2014). Further research should compare mobilizations in new democracies which went through different types of transitions, including pacted transitions (O'Donnell and Schmitter 1986). Cross-national studies can further improve our understanding of the interrelated effects of legacies of autocracy and transition on protest in young democracies.

Protest can be both a symptom of democratic consolidation and a powerful tool against democratic backsliding. As we have seen, however, the development of unconventional forms of participation is not automatic in new democracies. The past has a long shadow, and overcoming the legacies of the former authoritarian regime might take several decades.

\section{Acknowledgments}

I thank Bernhard Weßels for very useful comments and suggestions. An earlier version of this paper was presented at Humboldt University's Comparative Politics Colloquium. I thank the participants of the colloquium for their 
valuable comments. This study would not have been possible without the financial support of the Fonds de recherche du Québec - Société et culture (FRQSC) and the Fellowship Freies Wissen, sponsored by Wikimedia Deutschland, the Stifterverband, and the Volkswagen Foundation.

\section{Reproducibility}

The material to reproduce the analysis is available at: https:/github.com/ jolyphil/protest-DE.

\section{References}

Almond, Gabriel A. and Sidney Verba. 1963. The Civic Culture: Political Attitudes and Democracy in Five Nations. Princeton: Princeton University Press.

Barber, Benjamin R. 1984. Strong Democracy: Participatory Politics for a New Age. Berkeley: University of California Press.

Bartels, Larry M. and Simon Jackman. 2014. "A Generational Model of Political Learning." Electoral Studies 33:7-18.

Bernhagen, Patrick and Michael Marsh. 2007. "Voting and Protesting: Explaining Citizen Participation in Old and New European Democracies." Democratization 14(1):44-72.

Bernhard, Michael and Ekrem Karakoç. 2007. "Civil Society and the Legacies of Dictatorship." World Politics 59(4):539-567.

Brady, Henry E., Sidney Verba, and Kay Lehman Schlozman. 1995. "Beyond SES: A Resource Model of Political Participation." American Political Science Review 89(2):271-294.

Brenke, Karl. 2014. “Eastern Germany Still Playing Economic Catch-Up." DIW Economic Bulletin 4(11):6-23.

Caren, Neal, Raj Andrew Ghoshal, and Vanesa Ribas. 2011. "A Social Movement Generation: Cohort and Period Trends in Protest Attendance and Petition Signing." American Sociological Review 76(1):125-51.

Eisinger, Peter K. 1973. "The Conditions of Protest Behavior in American Cities." American Political Science Review 67(1):11-28.

Ekiert, Grzegorz and Jan Kubik. 1998. "Contentious Politics in New Democracies: East Germany, Hungary, Poland, and Slovakia, 1989-93." World Politics 50(4):547-81.

ESS. 2017. European Social Survey, Rounds 1-8 Data: Germany. Bergen: NSD - Norwegian Centre for Research Data, Data Archive and distributor of Ess data for Ess ERIC. 
EVS. 2015. European Values Study Longitudinal Data File 1981-2008, ZA4804 Data File, Version 3.o.o. Cologne: GES IS Data Archive.

Fishman, Robert M. 2017. "How Civil Society Matters in Democratization: Setting the Boundaries of Post-Transition Political Inclusion." Comparative Politics 49(3):391-409.

Grasso, Maria T. 2016. Generations, Political Participation and Social Change in Western Europe. Abingdon, Oxon: Routledge.

Gurr, Ted R. 1970. Why Men Rebel? Princeton: Princeton University Press.

Hooghe, Marc and Ellen Quintelier. 2014. "Political Participation in European Countries: The Effect of Authoritarian Rule, Corruption, Lack of Good Governance and Economic Downturn." Comparative European Politics 12(2):209-32.

Jennings, M. Kent. 1987. "Residues of a Movement: The Aging of the American Protest Generation." American Political Science Review 81(2):367-382.

Kaase, Max. 2007. "Perspectives on Political Participation." Pp. 783-96 in The Oxford Handbook of Political Behavior, edited by R. J. Dalton and H.-D. Klingemann. Oxford: Oxford University Press.

Kitschelt, Herbert. 1986. "Political Opportunity Structures and Political Protest: Anti-Nuclear Movements in Four Democracies." British Journal of Political Science 16(1):57-85.

Kitschelt, Herbert, Zdenka Mansfeldova, Radoslaw Markowski, and Gábor Tóka. 1999. Post-Communist Party Systems: Competition, Representation, and Inter-Party Cooperation. Cambridge: Cambridge University Press.

Kriesi, Hanspeter, Ruud Koopmans, Jan Willem Duyvendak, and Marco G. Giugni. 1995. New Social Movements in Western Europe: A Comparative Analysis. Minneapolis: University of Minnesota Press.

Lahusen, Christian and Lisa Bleckmann. 2015. "Beyond the Ballot Box: Changing Patterns of Political Protest Participation in Germany (1974-2008)." German Politics 24(3):402-26.

Linz, Juan J. 1975. "Totalitarian and Authoritarian Regimes." Pp. 175-411 in Handbook of Political Science. Vol. 3: Macropolitical Theory, edited by F. I. Greenstein and N. W. Polsby. Reading: Addison-Wesley.

Lohmann, Susanne. 1994. "The Dynamics of Informational Cascades: The Monday Demonstrations in Leipzig, East Germany, 1989-91." World Politics 47(1):42-101.

Mannheim, Karl. 1952. "The Problem of Generations." Pp. 276-322 in Essays on the Sociology of Knowledge, edited by P. Kecskemeti. London: Routledge and Kegan Paul.

McAdam, Doug. 1999. “The Biographical Impact of Activism.” Pp. 117-46 in How Social Movements Matter, edited by M. Giugni, D. McAdam, and C. Tilly. Minneapolis: University of Minnesota Press. 
McCarthy, John D. and Mayer N. Zald. 1977. "Resource Mobilization and Social Movements: A Partial Theory." American Journal of Sociology 82(6):1212-41.

Meyer, David S. and Nancy Whittier. 1994. "Social Movement Spillover." Social Problems 41(2):277-98.

Mishler, William and Richard Rose. 2007. "Generation, Age, and Time: The Dynamics of Political Learning during Russia's Transformation.” American Journal of Political Science 51(4):822-34.

Neundorf, Anja. 2010. "Democracy in Transition: A Micro Perspective on System Change in Post-Socialist Societies.” Journal of Politics 72(4):1096-1108.

Norris, Pippa. 2002. Democratic Phoenix: Reinventing Political Activism. Cambridge: Cambridge University Press.

O’Donnell, Guillermo and Philippe C. Schmitter. 1986. Transitions from Authoritarian Rule: Tentative Conclusions about Uncertain Democracies. Baltimore: Johns Hopkins University Press.

Oesch, Daniel. 2006a. "Coming to Grips with a Changing Class Structure: An Analysis of Employment Stratification in Britain, Germany, Sweden and Switzerland." International Sociology 21(2):263-88.

Oesch, Daniel. 2006b. Redrawing the Class Map: Stratification and Institutions in Britain, Germany, Sweden and Switzerland. Houndmills, Basingstoke, Hampshire: Palgrave Macmillan.

Opp, Karl-Dieter, Peter Voss, and Christiane Gern. 1995. Origins of a Spontaneous Revolution: East Germany, 1989. Ann Arbor: University of Michigan Press.

Oswald, Ingrid and Viktor Voronkov. 2004. "The 'Public-Private' Sphere in Soviet and Post-Soviet Society: Perception and Dynamics of 'Public' and 'Private' in Contemporary Russia." European Societies 6(1):97-117.

Pop-Eleches, Grigore and Joshua A. Tucker. 2013. "Associated with the Past? Communist Legacies and Civic Participation in Post-Communist Countries." East European Politics and Societies 27(1):45-68.

Pop-Eleches, Grigore and Joshua A. Tucker. 2017. Communism's Shadow: Historical Legacies and Contemporary Political Attitudes. Princeton: Princeton University Press.

Pop-Eleches, Grigore and Joshua A. Tucker. 2014. "Communist Socialization and PostCommunist Economic and Political Attitudes.” Electoral Studies 33:77-89.

della Porta, Donatella. 2014. Mobilizing for Democracy: Comparing 1989 and 2011. Oxford: Oxford University Press.

della Porta, Donatella. 2016. Where Did the Revolution Go? Contentious Politics and the Quality of Democracy. New York: Cambridge University Press.

Quaranta, Mario. 2016. “An Apathetic Generation? Cohorts' Patterns of Political Participation in Italy." Social Indicators Research 125(3):793-812. 
Robertson, Graeme B. 2011. The Politics of Protest in Hybrid Regimes: Managing Dissent in Post-Communist Russia. New York: Cambridge University Press.

Rodon, Toni and Marc Guinjoan. 2018. "Mind the Protest Gap: The Role of Resources in the Face of Economic Hardship." PS: Political Science \& Politics 51(1):84-92.

Roller, Edeltraud and Bernhard Weßels. 1996. "Contexts of Political Protest in Western Democracies: Political Organization and Modernity." Pp. 91-134 in Research on Democracy and Society. Vol. 3: Extremism, Protest, Social Movements, and Democracy, edited by F. D. Weil. Greenwich: JaI Press.

Rucht, Dieter. 1998. "The Structure and Culture of Collective Protest in Germany since 1950." Pp. 29-57 in The Social Movement Society: Contentious Politics for a New Century, edited by D. S. Meyer and S. Tarrow. Lanham: Rowman \& Littlefield Publishers.

Statistische Ämter des Bundes und der Länder. 2018. "Regional Accounts VGRdL: Inhabitants 1991 to 2017 (WZ 2008).” Retrieved (https://www.statistik-bw.de/ VGRdL/tbls/tab.jsp?lang=en-GB\&rev=RV2014\&tbl=tab20).

Statistische Ämter des Bundes und der Länder. 2016. "Regional Accounts VGRdL: Primary Income of the Private Households 1991 to 2015 (WZ 2008)." Retrieved (https:// www.statistik-bw.de/VGRdL/tbls/tab.jsp?lang=en-GB\&rev=RV2014\&tbl=tab13).

Tarrow, Sidney. 1995. "Cycles of Collective Action: Between Moments of Madness and the Repertoire of Contention." Pp. 89-115 in Repertoires and Cycles of Collective Action, edited by Mark Traugott. Durham: Duke University Press.

Tilly, Charles. 1978. From Mobilization to Revolution. New York: Random House.

Weßels, Bernhard. 2003. "Die Entwicklung der Zivilgesellschaft in Mittel- und Osteuropa: Intermediäre Akteure, Vertrauen und Partizipation.” Pp. 173-98 in Zivilgesellschaft:Bedingungen, Pfade, Abwege. WZB-Jahrbuch 2003, edited by D. Gosewinkel, D. Rucht, W. van den Daele, and J. Kocka. Berlin: Edition Sigma.

Wielgohs, Jan. 2008. "DDR - regimekritische und politisch-alternative Akteure (19491990)." Pp. 109-31 in Die sozialen Bewegungen in Deutschland seit 1945, edited by R. Roth and D. Rucht. Frankfurt am Main: Campus Verlag.

Yang, Yang and Kenneth C. Land. 2006. "A Mixed Models Approach to the Age-PeriodCohort Analysis of Repeated Cross-Section Surveys, with an Application to Data on Trends in Verbal Test Scores." Sociological Methodology 36(1):75-97.

Yang, Yang and Kenneth C. Land. 2008. "Age-Period-Cohort Analysis of Repeated Cross-Section Surveys: Fixed or Random Effects?" Sociological Methods \& Research 36(3):297-326.

Zolberg, Aristide R. 1972. "Moments of Madness." Politics \& Society 2(2):183-207. 


\section{Appendices}

\section{Regression Tables}

TABLE A1 APC models of protest participation: random slopes at the cohort level

Demonstration Petition Boycott

Coef. SE Coef. SE Coef. SE

Individual-level variables

\begin{tabular}{|c|c|c|c|c|c|c|}
\hline East German & $-0.2881^{*}$ & $(0.1284)$ & $-0.2362^{*}$ & $(0.0920)$ & $-0.3719^{* * *}$ & $(0.1010)$ \\
\hline Woman & $-0.1630^{* *}$ & $(0.0543)$ & $0.2394^{* * *}$ & $(0.0328)$ & $0.2527^{* * *}$ & $(0.0347)$ \\
\hline Age (10 years) & -0.1779 & $(0.1490)$ & $0.3864^{* * *}$ & $(0.0764)$ & $0.6688 * * *$ & $(0.0759)$ \\
\hline $\mathrm{Age}^{2}$ & -0.0102 & $(0.0144)$ & $-0.0503^{* * *}$ & $(0.0073)$ & $-0.0766^{* * *}$ & $(0.0072)$ \\
\hline \multicolumn{7}{|l|}{ Education $($ ref. $=$ Low $)$} \\
\hline Middle & $0.3022 *$ & $(0.1278)$ & $0.4042^{* * *}$ & $(0.0692)$ & $0.4433^{* * *}$ & $(0.0740)$ \\
\hline High & $0.7446^{* * *}$ & $(0.1434)$ & $0.8323^{* * *}$ & $(0.0819)$ & $0.7854^{* * *}$ & $(0.0868)$ \\
\hline Unemployed & $0.3318^{* *}$ & $(0.1065)$ & $-0.1692 *$ & $(0.0748)$ & -0.1225 & $(0.0827)$ \\
\hline Union member & $0.6049^{* * *}$ & $(0.0590)$ & $0.3097^{* * *}$ & $(0.0361)$ & $0.2053^{* * *}$ & $(0.0381)$ \\
\hline \multirow{2}{*}{\multicolumn{7}{|c|}{$\begin{array}{l}\text { Town size }(\text { ref. }=\text { Home in } \\
\text { countryside })\end{array}$}} \\
\hline & & & & & & \\
\hline Country village & $-0.3958^{+}$ & $(0.2095)$ & -0.1140 & $(0.1191)$ & -0.1116 & $(0.1205)$ \\
\hline Town or small city & -0.0041 & (o.2069) & $-0.005^{2}$ & $(0.1188)$ & -0.0620 & $(0.1202)$ \\
\hline Outskirts of big city & 0.1688 & $(0.2131)$ & 0.0892 & $(0.1237)$ & 0.0406 & $(0.1253)$ \\
\hline A big city & $0.4841^{*}$ & $(0.2122)$ & $0.2466^{*}$ & $(0.1243)$ & 0.1671 & $(0.1263)$ \\
\hline \multirow{2}{*}{\multicolumn{7}{|c|}{$\begin{array}{l}\text { Social class (ref. }=\text { High } \\
\text { service class) }\end{array}$}} \\
\hline & & & & & & \\
\hline Low service class & -0.0423 & $(0.0846)$ & -0.0446 & $(0.0553)$ & $-0.1743^{* *}$ & (0.0573) \\
\hline Small business owners & $-0.2418^{*}$ & $(0.1163)$ & $-0.1854^{* *}$ & $(0.0697)$ & -0.0320 & $(0.0710)$ \\
\hline Skilled workers & $-0.3623^{* * *}$ & (o.0903) & $-0.436 o^{* * *}$ & $(0.0565)$ & $-0.5391^{* * *}$ & $(0.0591)$ \\
\hline Unskilled workers & $-0.5135^{* * *}$ & $(0.1181)$ & $-0.6271^{* * *}$ & $(0.0703)$ & $-0.6871^{* * *}$ & $(0.0742)$ \\
\hline
\end{tabular}

State fixed effects $($ ref. $=$

Baden-Württemberg)

$\begin{array}{lllllll}\text { Bavaria } & -0.1724 & (0.1153) & 0.2140^{* *} & (0.0678) & -0.1529^{*} & (0.0674) \\ \text { Berlin } & 0.203^{2} & (0.1512) & 0.2216^{*} & \left(0.105^{8}\right) & -0.3345^{* *} & (0.1087) \\ \text { Brandenburg } & 0.4690^{* *} & (0.1702) & 0.2455^{*} & (0.1141) & -0.6207^{* * *} & (0.1211) \\ \text { Bremen } & 0.0095 & (0.2751) & -0.0517 & (0.1905) & 0.0138 & (0.1880) \\ \text { Hamburg } & 0.0927 & (0.1956) & -0.0468 & (0.1402) & -0.3636^{*} & (0.1421)\end{array}$


TABLE A1 APC models of protest participation: random slopes at the cohort level (cont.)

\begin{tabular}{|c|c|c|c|c|c|c|}
\hline & \multicolumn{2}{|c|}{ Demonstration } & \multicolumn{2}{|l|}{ Petition } & \multicolumn{2}{|l|}{ Boycott } \\
\hline & Coef. & SE & Coef. & SE & Coef. & SE \\
\hline Hesse & -0.0985 & $(0.1401)$ & $-0.045^{0}$ & $(0.0850)$ & $-0.2668^{* *}$ & $(0.0844)$ \\
\hline Mecklenburg- & 0.2125 & $(0.1897)$ & 0.0639 & $(0.1236)$ & $-0.8503^{* * *}$ & $(0.1364)$ \\
\hline Vorpommern & & & & & & \\
\hline Lower Saxony & -0.2038 & $(0.1337)$ & $-0.1904 *$ & $(0.0789)$ & $-0.4014^{* * *}$ & $(0.0778)$ \\
\hline $\begin{array}{l}\text { North Rhine- } \\
\text { Westphalia }\end{array}$ & $-0.3619^{* * *}$ & $(0.1084)$ & $-0.1273^{*}$ & $(0.0648)$ & $-0.4023^{* * *}$ & $(0.0642)$ \\
\hline Rhineland-Palatinate & $-0.3514^{*}$ & $(0.1788)$ & -0.1388 & $(0.0974)$ & $-0.3926^{* * *}$ & $(0.0968)$ \\
\hline Saarland & $-0.6643^{+}$ & $(0.4001)$ & -0.2871 & $(0.1938)$ & -0.1515 & $(0.1843)$ \\
\hline Saxony & 0.0480 & $(0.1687)$ & -0.0634 & $(0.1106)$ & $-0.6179^{* * *}$ & $(0.1154)$ \\
\hline Saxony-Anhalt & -0.1591 & $(0.1898)$ & $0.2297^{+}$ & $(0.1174)$ & $-0.9347^{* * *}$ & $(0.1303)$ \\
\hline Schleswig-Holstein & 0.0051 & $(0.1767)$ & 0.1690 & $(0.1060)$ & $-0.2915^{* *}$ & $(0.1077)$ \\
\hline Thuringia & 0.0654 & $(0.1853)$ & $0.2262^{+}$ & $(0.1177)$ & $-0.6202^{* * *}$ & $(0.1260)$ \\
\hline Intercept & $-1.4831^{* * *}$ & $(0.4347)$ & $-1.5968^{* * *}$ & $(0.2426)$ & $-1.9253^{* * *}$ & $(0.2581)$ \\
\hline $\begin{array}{l}\text { Variance (period: } \\
\text { intercept) }\end{array}$ & 0.0148 & $(0.0104)$ & 0.0190 & $(0.0106)$ & 0.0704 & $(0.0364)$ \\
\hline Variance (cohort: slope) & 0.0019 & $(0.0121)$ & 0.0105 & $(0.0096)$ & 0.0235 & $(0.0167)$ \\
\hline $\begin{array}{l}\text { Variance (cohort: } \\
\text { intercept) }\end{array}$ & 0.0198 & $(0.0127)$ & 0.0013 & $(0.0022)$ & 0.0000 & (0.0000) \\
\hline BIC & 10829.2 & & 23236.1 & & 21439.0 & \\
\hline $\mathrm{N}$ (periods) & 8 & & 8 & & 8 & \\
\hline $\mathrm{N}$ (cohorts) & 14 & & 14 & & 14 & \\
\hline $\mathrm{N}$ (individuals) & 18722 & & 18683 & & 18689 & \\
\hline
\end{tabular}

Note: Significance: ${ }^{+} p<0.1 ;{ }^{*} p<0.05 ;{ }^{* *} p<0.01 ;{ }^{* * *} p<0.001$. Results with logit estimates and standard errors.

SOURCE: ESS 2017. 
TABLE A2 APC models of protest participation: random slopes at the period level

Demonstration Petition Boycott

Coef. SE Coef. SE Coef. SE

\section{Individual-level variables}

\begin{tabular}{|c|c|c|c|c|c|c|}
\hline East German & $-0.315^{*}$ & $(0.1459)$ & $-0.2542^{* *}$ & $(0.0986)$ & $-0.3792^{* * *}$ & $(0.0929)$ \\
\hline Woman & $-0.1637^{* *}$ & $(0.0543)$ & $0.2371^{* * *}$ & $(0.0328)$ & $0.2498^{* * *}$ & $(0.0346)$ \\
\hline Age (10 years) & -0.1829 & $(0.1470)$ & $0.3595^{* * *}$ & $(0.0680)$ & $0.6284^{* * *}$ & $(0.0704)$ \\
\hline $\mathrm{Age}^{2}$ & -0.0093 & $(0.0142)$ & $-0.0480^{* * *}$ & $(0.0065)$ & $-0.0740^{* * *}$ & (o.0o68) \\
\hline \multicolumn{7}{|l|}{ Education $($ ref. $=$ Low $)$} \\
\hline Middle & $0.3001 *$ & $(0.1279)$ & $0.4024^{* * *}$ & $(0.0692)$ & $0.4448^{* * *}$ & $(0.0740)$ \\
\hline High & $0.7442^{* * *}$ & $(0.1436)$ & $0.8259^{* * *}$ & $(0.0819)$ & $0.7791^{* * *}$ & $(0.0867)$ \\
\hline Unemployed & $0.3104^{* *}$ & (o.1069) & $-0.1844^{*}$ & $(0.0748)$ & -0.1310 & $(0.0826)$ \\
\hline Union member & $0.5937^{* * *}$ & $(0.0589)$ & $0.2987^{* * *}$ & $(0.0356)$ & $0.1840^{* * *}$ & $(0.0372)$ \\
\hline \multirow{2}{*}{\multicolumn{7}{|c|}{$\begin{array}{l}\text { Town size (ref. = Home in } \\
\text { countryside) }\end{array}$}} \\
\hline & & & & & & \\
\hline Country village & $-0.4020^{+}$ & $(0.2096)$ & -0.1192 & $(0.1192)$ & -0.1124 & $(0.1205)$ \\
\hline Town or small city & -0.0063 & $(0.2070)$ & -0.0013 & $(0.1189)$ & -0.0602 & $(0.1203)$ \\
\hline Outskirts of big city & 0.1613 & $(0.2132)$ & 0.0940 & $(0.1237)$ & 0.0437 & $(0.1253)$ \\
\hline A big city & $0.4849^{*}$ & $(0.2123)$ & $0.2488^{*}$ & $(0.1244)$ & 0.1713 & $(0.1263)$ \\
\hline \multirow{2}{*}{\multicolumn{7}{|c|}{$\begin{array}{l}\text { Social class }(\text { ref. }=\text { High } \\
\text { service class })\end{array}$}} \\
\hline & & & & & & \\
\hline Low service class & -0.0396 & $(0.0847)$ & -0.0426 & $(0.0553)$ & $-0.1743^{* *}$ & $(0.0573)$ \\
\hline Small business owners & $-0.2401 *$ & $(0.1164)$ & $-0.1870^{* *}$ & $(0.0696)$ & -0.0334 & $(0.0709)$ \\
\hline Skilled workers & $-0.3584^{* * *}$ & $(0.0905)$ & $-0.4356^{* * *}$ & $(0.0565)$ & $-0.5411^{* * *}$ & $(0.0590)$ \\
\hline Unskilled workers & $-0.5078^{* * *}$ & $(0.1182)$ & $-0.6257^{* * *}$ & $(0.0702)$ & $-0.6895^{* * *}$ & $(0.0742)$ \\
\hline
\end{tabular}

State fixed effects $($ ref. $=$

Baden-Württemberg)

$\begin{array}{lllllll}\text { Bavaria } & -0.1737 & (0.1153) & 0.2112^{* *} & (0.0678) & -0.1549^{*} & (0.0674) \\ \text { Berlin } & 0.2062 & (0.1513) & 0.2180^{*} & (0.1059) & -0.3385^{* *} & (0.1086) \\ \text { Brandenburg } & 0.4918^{* *} & (0.1707) & 0.2614^{*} & (0.1143) & -0.6204^{* * *} & (0.1216) \\ \text { Bremen } & 0.0095 & (0.2751) & -0.0520 & (0.1907) & 0.0145 & (0.1881) \\ \text { Hamburg } & 0.0906 & (0.1955) & -0.0422 & (0.1403) & -0.3620^{*} & (0.1422) \\ \text { Hesse } & -0.0977 & (0.1400) & -0.0456 & (0.0851) & -0.2642^{* *} & (0.0845) \\ \text { Mecklenburg- } & 0.2220 & (0.1900) & 0.0677 & (0.1235) & -0.8545^{* * *} & (0.1363) \\ \text { Vorpommern } & & & & & & \end{array}$


TABLE A2 APC models of protest participation: random slopes at the period level (cont.)

\begin{tabular}{|c|c|c|c|c|c|c|}
\hline & \multicolumn{2}{|c|}{ Demonstration } & \multicolumn{2}{|l|}{ Petition } & \multicolumn{2}{|l|}{ Boycott } \\
\hline & Coef. & SE & Coef. & SE & Coef. & SE \\
\hline Lower Saxony & -0.1989 & $(0.1337)$ & $-0.1890^{*}$ & $(0.0789)$ & $-0.4000^{* * *}$ & $(0.0779)$ \\
\hline North Rhine-Westphalia & $-0.359^{* * *}$ & $(0.1084)$ & $-0.1280^{*}$ & $(0.0648)$ & $-0.4021^{* * *}$ & $(0.0643)$ \\
\hline Rhineland-Palatinate & $-0.3483^{+}$ & $(0.1788)$ & -0.1377 & $(0.0975)$ & $-0.3920^{* * *}$ & $(0.0968)$ \\
\hline Saarland & $-0.6599^{+}$ & $(0.4000)$ & -0.2859 & $(0.1940)$ & -0.1467 & $(0.1844)$ \\
\hline Saxony & 0.0617 & (o.169o) & -0.0579 & $(0.1106)$ & $-0.6197^{* * * *}$ & $(0.1156)$ \\
\hline Saxony-Anhalt & -0.1538 & $(0.1901)$ & $0.2348^{*}$ & $(0.1175)$ & $-0.9423^{* * *}$ & $(0.1305)$ \\
\hline Schleswig-Holstein & 0.0024 & $(0.1767)$ & 0.1665 & $(0.1061)$ & $-0.2893^{* *}$ & $(0.1078)$ \\
\hline Thuringia & $0.075^{\circ}$ & $\left(0.185^{8}\right)$ & $0.2312^{*}$ & $(0.1178)$ & $-0.6249^{* * *}$ & $(0.1262)$ \\
\hline Intercept & $-1.4744^{* * *}$ & $(0.4305)$ & $-1.515^{8 * *}$ & $(0.2273)$ & $-1.7858^{* * *}$ & $(0.2468)$ \\
\hline Variance (cohort: intercept) & 0.0196 & $(0.0123)$ & 0.0005 & $(0.0017)$ & 0.0000 & $(0.0000)$ \\
\hline Variance (period: slope) & 0.0392 & $(0.0298)$ & 0.0173 & $(0.0132)$ & 0.0032 & $(0.0073)$ \\
\hline Variance (period: intercept) & 0.0157 & $(0.0122)$ & 0.0279 & $(0.0156)$ & 0.0754 & $(0.0393)$ \\
\hline BIC & 10822.1 & & 23232.2 & & $21445 \cdot 7$ & \\
\hline $\mathrm{N}$ (cohorts) & 14 & & 14 & & 14 & \\
\hline $\mathrm{N}$ (periods) & 8 & & 8 & & 8 & \\
\hline $\mathrm{N}$ (individuals) & 18722 & & 18683 & & 18689 & \\
\hline
\end{tabular}

Note: Significance: ${ }^{+} p<0.1 ;{ }^{*} p<0.05 ;{ }^{* *} p<0.01 ;{ }^{* * *} p<0.001$. Results with logit estimates and standard errors.

SOURCE: ESS 2017. 


\section{Fixed Effects Models: Figures}

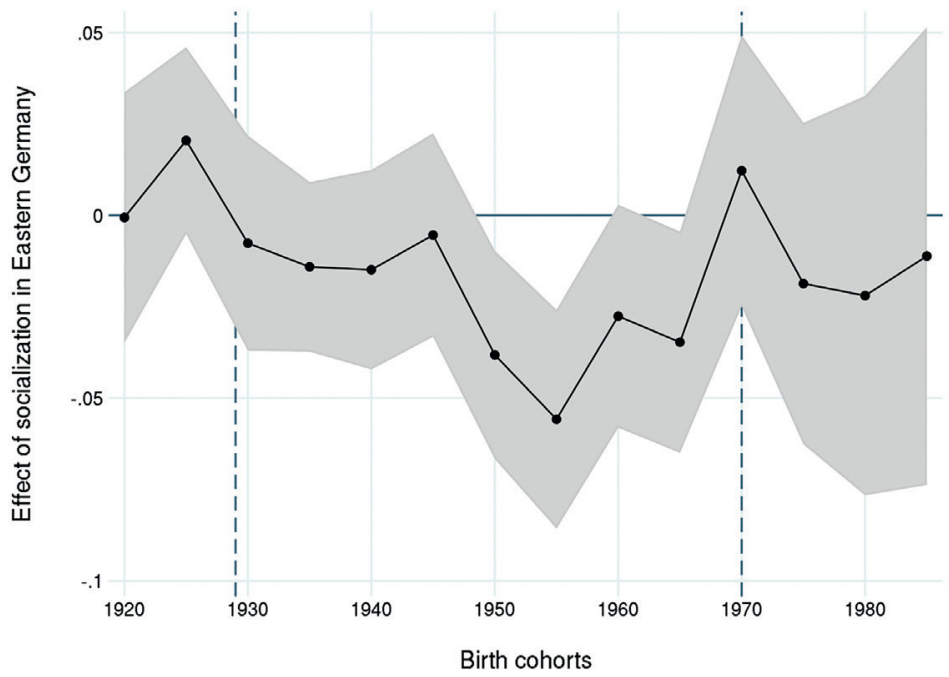

Note: Based on fixed effects model with interaction terms. Vertical dotted lines indicate the separations between the pre-, post-, and Cold War generations. Grey areas show $95 \%$ confidence intervals of the fixed effects.

FIGURE A1 Effect of socialization in Eastern Germany on demonstration attendance across cohorts ESS 2017

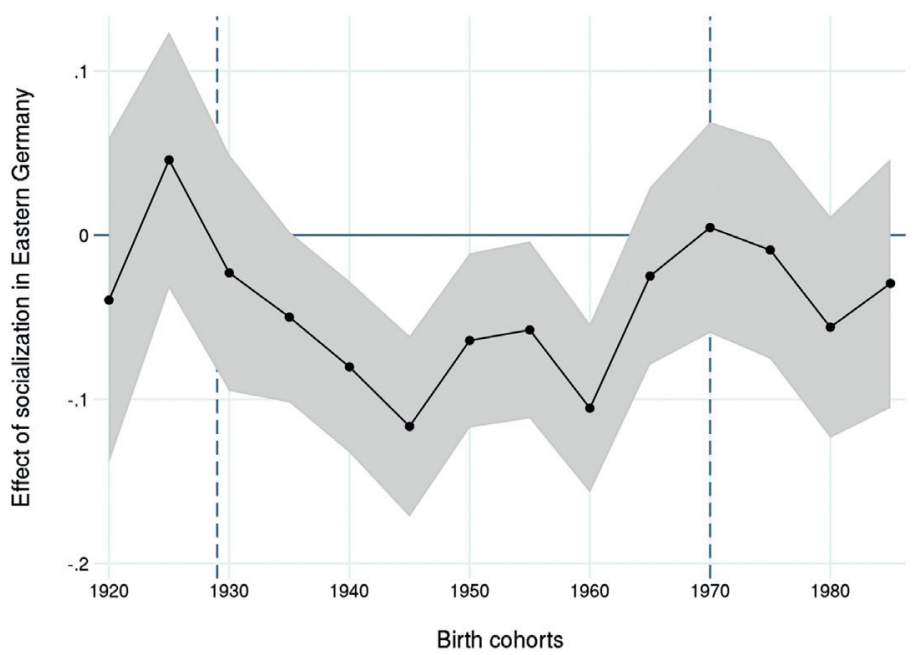

Note: Based on fixed effects model with interaction terms. Vertical dotted lines indicate the separations between the pre-, post-, and Cold War generations. Grey areas show $95 \%$ confidence intervals of the fixed effects.

FIGURE A2 Effect of socialization in Eastern Germany on petition signing across cohorts

ESS 2017 


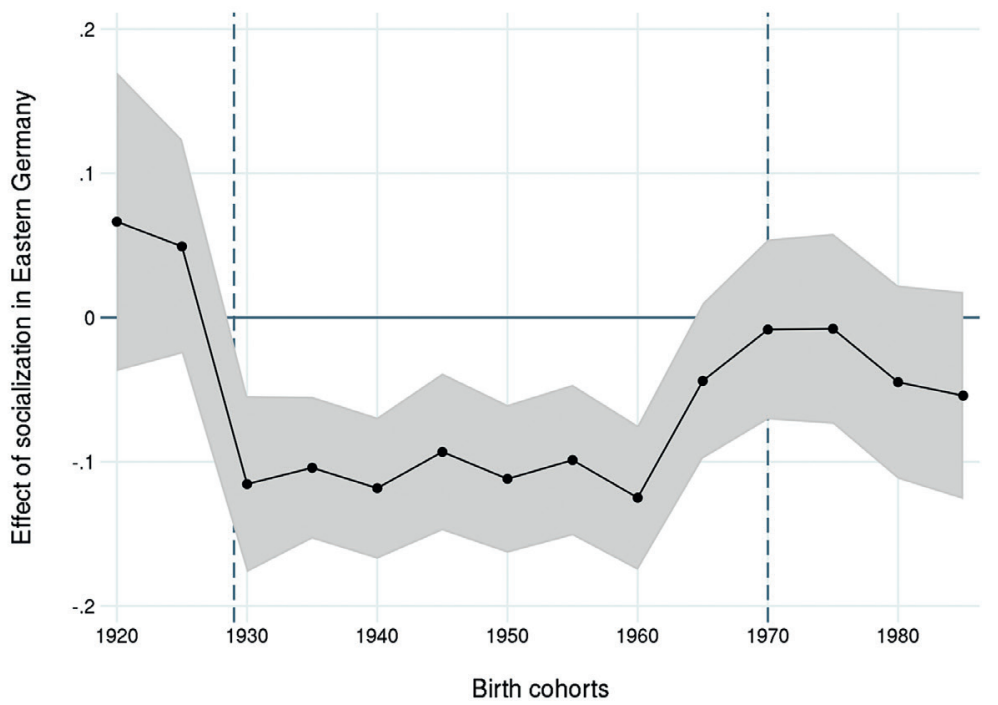

Note: Based on fixed effects model with interaction terms. Vertical dotted lines indicate the separations between the pre-, post-, and Cold War generations. Grey areas show $95 \%$ confidence intervals of the fixed effects.

FIGURE A3 Effect of socialization in Eastern Germany on participation in boycotts across cohorts

ESS 2017

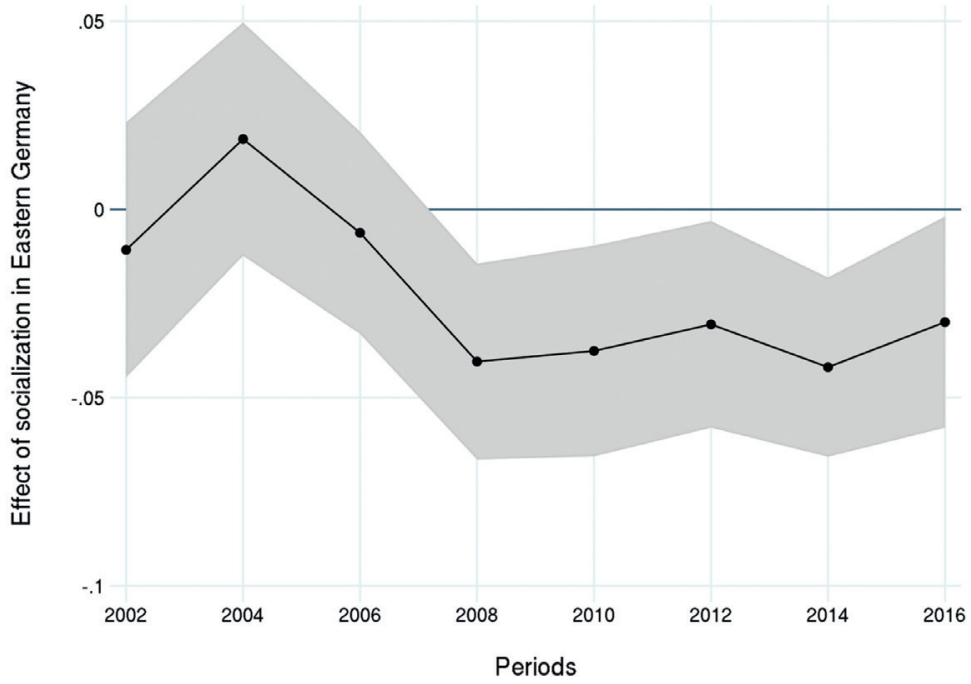

Note: Based on fixed effects model with interaction terms. Grey areas show 95\% confidence intervals of the fixed effects.

FIGURE A4 Effect of socialization in Eastern Germany on demonstration attendance across periods

ESS 2017 


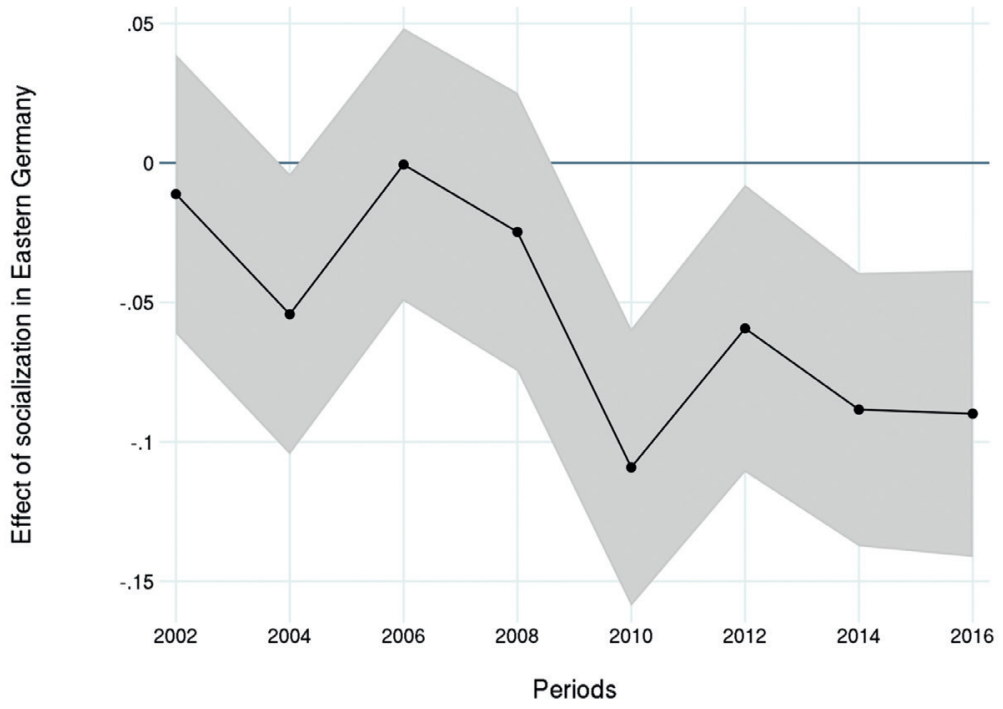

Note: Based on fixed effects model with interaction terms. Grey areas show 95\% confidence intervals of the fixed effects.

FIGURE A5 Effect of socialization in Eastern Germany on petition signing across periods

ESS 2017

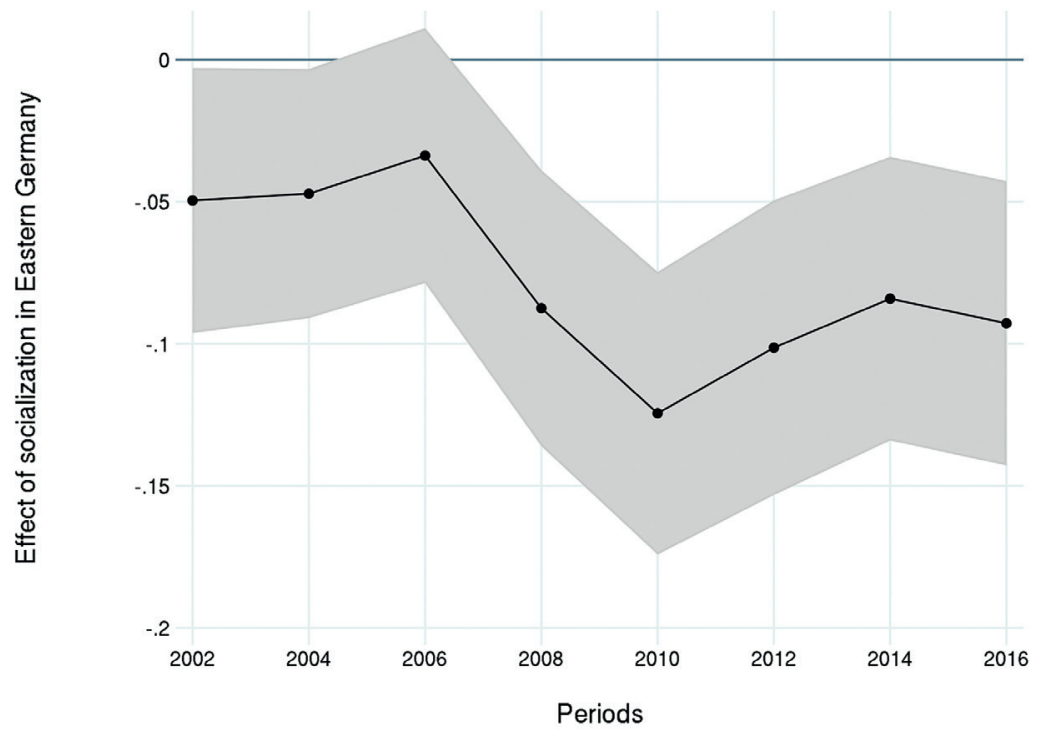

Note: Based on fixed effects model with interaction terms. Grey areas show 95\% confidence intervals of the fixed effects.

FIGURE A6 Effect of socialization in Eastern Germany on participation in boycotts across periods

ESS 2017 